\title{
BMJ Open Portuguese version of a stress and well-being evaluation tool (ASSET) at the workplace: validation of the psychometric properties
}

Maria João Heitor dos Santos, ${ }^{1,2}$ Sérgio Moreira, ${ }^{1,3}$ Joana Carreiras, ${ }^{1}$
Cary Cooper,

To cite: Heitor dos Santos MJ, Moreira S, Carreiras J, et al. Portuguese version of a stress and well-being evaluation tool (ASSET)at the workplace: validation of the psychometric properties. BMJ Open 2018;8:e018401. doi:10.1136/ bmjopen-2017-018401

- Prepublication history and additional material for this paper are available online. To view these files, please visit the journal online (http://dx.doi org/10.1136/bmjopen-2017018401).

Received 6 July 2017 Revised 21 November 2017 Accepted 27 November 2017

\section{Check for updates}

${ }^{1}$ Institute of Preventive Medicine \& Public Health (IMP\&SP) and Institute of Environmental Health (ISAMB), Faculty of Medicine, University of Lisbon (FMUL), Lisbon, Portugal

${ }^{2}$ Psychiatry and Mental Health Department, Hospital Beatriz Ângelo, Loures, Portugal ${ }^{3}$ Faculty of Psychology, University of Lisbon, Lisbon, Portugal

${ }^{4}$ Manchester Business School, University of Manchester,

Manchester, UK

${ }^{5}$ Robertson Cooper Ltd,

Manchester, UK

\section{Correspondence to}

Dr Maria João Heitor dos

Santos; mjhsantos@netcabo.pt and Cary Cooper;

cary.cooper@manchester.ac.uk

\section{ABSTRACT}

Objective The main objective of this work was to translate the English version of ASSET (A Shortened Stress Evaluation Tool) into the Portuguese version and to validate its psychometric properties. Additionally, this work tested the convergent validity of the instrument.

Methods The translation and retroversion were conducted by experts and submitted to the authors for approval. Within an observational, cross-sectional study, regarding mental health at the workplace, ASSET together with other scales was applied to a sample of 405 participants. The psychometric validity of the subscales was studied using confirmatory factorial analysis.

Results The factorial structure of ASSET is globally supported by the results, with the Perceptions of Your Job and Attitudes Towards your Organisation subscales requiring slight adjustments in the item structure and the Your Health subscales replicating the original structure. The convergent validity also supports the ASSET, showing that all subscales are significantly correlated with variables used to test convergence.

Conclusions Globally, the results constitute an important contribution to ASSET and open the possibility of its usage among Portuguese-speaking countries. The results provide an evidence on the validity of the instrument and, in particular, of the mental and physical health subscales.

\section{INTRODUCTION}

Working conditions, job organisation and environment and work-family conflict have a significant impact on mental health and wellbeing. According to the Health and Safety Executive health statistics, work-related stress accounts for $37 \%$ of work-related ill health and $45 \%$ of days lost, in 2015-2016. Workload, in particular tight deadlines, too much work and too much pressure or responsibility, a lack of managerial support, organisational changes at work, violence and role uncertainty are identified causes of work-related stress. ${ }^{1}$ These factors are antecedents of sickness presenteeism which is mediated by mental and physical health. ${ }^{2}$ At the individual level,

\section{Strengths and limitations of this study}

- Offers an accurate translated version of ASSET (A Shortened Stress Evaluation Tool) to be used by Portuguese language countries.

- Uses a large sample and a detailed procedure for confirmatory factorial analysis to report the psychometric properties of ASSET.

- Describes which scales fully replicate the original results and provides cautionary notes and potential accounts for the scales that do not fully replicate the original results.

- Tests the convergent validity of the ASSET, in particular, the Physical Health and Psychological Well-Being subscales, using validated instruments and a set of biometric measures.

- The two versions of ASSET (the original English version and the Portuguese one) do broadly relate to each other, and our results are favourable to the utilisation of ASSET, in general, and unequivocally of the health subscales; however, the results of the two subscales 'Perceptions of Your Job' and 'Attitudes Towards your Organisation' show a few discrepancies, and minor adjustments were required, probably reflecting either some limitations of the items or their adaptation to the Portuguese culture, and this requires further consideration.

chronic stress produces long-term deleterious effects in health, namely, cardiovascular diseases, ${ }^{3}$ burn-out, anxiety and depression. ${ }^{4}$ Sickness absence in Europe is associated with psychosocial work factors. ${ }^{5}$ The link between work performance, stress and health poses an important challenge to workers, employers and organisations in general, as stress should be monitored and mitigation measures implemented accordingly. ${ }^{6}$

ASSET- A Shortened Stress Evaluation Tool-was developed by Faragher et $a l^{7}$ to evaluate the factors associated with the risk of stress of workers in an organisation. More specifically, this instrument measures 
Table 1 Sample characterisation

\begin{tabular}{lllll}
\hline Age & Sex & Habilitations & Functional group & Work regime \\
\hline Mean=41.2 & $48.6 \%$ males & $31.6 \%$ undergraduates & $14.8 \%$ managers & $99.0 \%$ full time \\
$\mathrm{SD}=8.3$ & & $6.6 \%$ graduates & $32.3 \%$ technicians & $1.0 \%$ part time \\
$\operatorname{Min}=22.0$ & & $21.8 \%$ postgraduates & $34.8 \%$ commercials & \\
$M a x=64.0$ & & & $18.0 \%$ administrative & \\
\hline
\end{tabular}

Max, maximum; Min, minimum.

the exposure to stress by taking into account both work stress sources (ie, work relationships (WR), overload $(\mathrm{O})$, control (C), job security (JS), resources and communication (RC), work-life balance (WLB), pay and benefits $(\mathrm{PB})$ and job $(\mathrm{J}))$ and work stress effects (ie, commitment of employee to organisation (CEO), perceived commitment of organisation to employee (COE) and Physical Health (PH) and Psychological Well-Being (PWB); online supplementary figure 1). This model underlying the ASSET is based on Cooper and Marshall ${ }^{8}$ and acknowledges that CEO and the perceived COE can work not only as a result but also as a source of stress.

ASSET is a self-report instrument that allows monitoring the workers' stress levels in an organisation, as well as how different departments are affected and contribute to these stress outcomes. It also provides normative data that allow comparisons with other similar organisations and sectors as well as providing an organisational profile. ${ }^{7}$

Faragher $e t a l^{7}$ validated the factorial structure of each of the subscales in two empirical studies, one using Exploratory Factorial Analysis to identify the structure and another using confirmatory factorial analysis (CFA) to corroborate the structure. ${ }^{6}$ Additionally, ASSET has been empirically validated. In other studies, for instance, Donald and collaborators, in a study with 16000 employers of 15 English companies, replicated the factorial structure of the instrument and tested with success for the relationships of some of the subscales and productivity. ${ }^{6}$ In another study, Johnson and Cooper reported a significant correlation between the PWB subscale and the General Health Questionnaire in a sample with 60 administrative workers. ${ }^{9}$ In addition, Cartwright and Cooper showed that the Perceptions of Your Job (PYJ) had a significant correlation with Warr's Work Satisfaction Scale. ${ }^{10} 11$ Finally, besides the empirical support, ASSET has been extensively used in an organisational context. It was used in a national level study in England to identify professions with higher stress levels, ${ }^{12}$ and it was used to test the relations between productivity, health and work stress. ${ }^{9}$ Despite its international relevance and usage as a measure of stress in organisations, ${ }^{1314}$ the instrument lacks a Portuguese version that can be used by the Community of Portuguese Language Countries, ${ }^{15}$ that is estimated to be more than 270 million people. In this sense, the main objective of this paper is to assess the efficacy of ASSET for use in a Portuguese language context. A second objective is to provide additional convergent validity for ASSET subscales, particularly for PH and PWB.

\section{METHOD}

A survey was conducted within a project on Health Impact Assessment of Employment Strategies in Portugal, under two collaboration protocols between the Institute of Preventive Medicine and Public Health of the Faculty of Medicine, University of Lisbon (FMUL), the Portuguese National Institute of Health (INSA, IP), and the Office of the High Commissioner for Health, followed by the Directorate General of Health. This survey had two components, respectively, psychosocial and biological. ASSET and a set of other measures were used to test the convergent validity. This research was approved by two institutional ethical committees, the Ethics Committee for Health of the National Institute of Health Doutor Ricardo Jorge, Public Institute (INSA, IP) and the Ethics Committee for Health of the Lisbon/North Hospital Centre of FMUL. It was also approved by the National Commission of Data Protection. All the participants signed an informed consent. This research was conducted under the Helsinki declaration code of ethics.

\section{Participants}

Our non-probabilistic sample consists of 405 participants, workers at a private mutual financial institution-Associação Mutualista Caixa Económica Montepio Geral (CEMG, table 1). A preliminary list of participants was assembled by the CEMG, and an invitation to participate in the study was sent to all workers. Those who voluntarily replied were enrolled in the study.

The average age was 41.2 years (SD 8.3), approximately half were males, and the majority were graduates $(46.6 \%$ bachelors and $21.8 \%$ masters); $14.8 \%$ had management roles, $32.3 \%$ technical, $34.8 \%$ commercial and $18.0 \%$ performed administrative roles.

\section{Instruments}

ASSET tool

Self-report instrument measures individual's perceptions regarding stress, well-being and engagement at work. Its theoretical background comes from classic models of stress, ${ }^{8}$ it was developed by Cary Cooper and Susan Cartwright ${ }^{7}$ and is used as a screening tool for job stress issues. ${ }^{16}$ It is composed of four themes, with a total of 12 subscales (online supplementary table 1 ). Theme 1 provides bibliographical information. Theme 2 refers to the PYJ and has a set of 37 items organised in seven subscales and one item: WR, O, C, JS, RC, WLB, J, and the single item $\mathrm{PB}$. Theme 3 refers to the Attitudes Towards 


\begin{tabular}{|c|c|c|c|c|c|}
\hline Theme & Subscale & Items & Mean & SD & Min-Max \\
\hline \multirow[t]{7}{*}{ PYJ } & WR & 5 of 8 & 2.32 & 0.78 & $1-5$ \\
\hline & $J$ & 3 of 8 & 2.20 & 0.75 & $1-6$ \\
\hline & $\mathrm{O}$ & 4 of 4 & 2.91 & 1.05 & $1-6$ \\
\hline & C & 2 of 4 & 2.84 & 1.17 & $1-6$ \\
\hline & JS & 4 of 4 & 2.44 & 0.85 & $1-5$ \\
\hline & $\mathrm{RC}$ & 3 of 4 & 2.72 & 0.98 & $1-6$ \\
\hline & WLB & 4 of 4 & 2.76 & 0.95 & $1-6$ \\
\hline \multirow[t]{2}{*}{ ATO } & CEO & 2 of 4 & 5.09 & 0.71 & $3-6$ \\
\hline & COE & 5 of 5 & 4.82 & 0.70 & $3-6$ \\
\hline \multirow[t]{2}{*}{$\mathrm{YH}$} & $\mathrm{PH}$ & 6 of 6 & 1.97 & 0.66 & $1-4$ \\
\hline & PWB & 11 of 11 & 1.95 & 0.65 & $1-4$ \\
\hline
\end{tabular}

ATO, Attitudes Towards your Organisation; C, control; CEO, commitment of employee to organisation; CFA, confirmatory factorial analysis; COE, commitment of organisation to employee; J, job; JS, job security; Min-Max, minimum and maximum; O, overload; PH, Physical Health; PWB, Psychological Well-Being; PYJ, Perceptions of Your Job; RC, resources and communication; WLB, work-life balance; WR, work relationships; YH, Your Health.

your Organisation (ATO) and comprises a set of nine items organised in two subscales: $\mathrm{CEO}$ and COE. Theme 4 refers to Your Health (YH) and is composed of a set of 17 items organised in two subscales: $\mathrm{PH}$ and PWB. The subscales for PYJ and ATO are measured on a 1 (totally disagree) to a 6 (totally agree) Likert scale. YH subscales are measured on a 1 (never) to 4 (frequently) scale. To allow for comparison with existing norms, the subscales can be standardised using 'sten' standardisation, a popular standard score for psychological assessment results that ranges from 1 to 10 , with a normal distribution, an average of 5.5 and an SD of $2 .{ }^{17}$ However, if the

Table 3 Descriptive data of the variables used for the test of the convergent validity

\begin{tabular}{llllrc}
\hline Name & Type & $\mathbf{n}$ & Mean/Fr & SD & Min- Max \\
\hline WSS & Scale & 405 & 4.38 & 1.03 & $1-7$ \\
PerH & Item & 405 & 1.38 & 0.52 & $1-3$ \\
Phy & Index & 405 & 3.14 & 1.45 & $1-6$ \\
Met & Index & 260 & At risk: 12\% & - & $0-1$ \\
Card & Index & 260 & 3.31 & 2.03 & $0-9$ \\
Med & Index & 405 & 2.58 & 1.66 & $1-9$ \\
MHI-5 & Scale & 405 & 68.91 & 18.97 & $4-100$ \\
SHS & Scale & 405 & 5.24 & 1.07 & $1-7$ \\
CD-RISC & Scale & 405 & 3.12 & 0.37 & $1.33-4$ \\
\hline
\end{tabular}

Card, cardiovascular risk; CD-RISC, Connor-Davidson Resilience Scale; Fr, frequency; Med, medication consumption; Met, metabolic syndrome; MHI, Mental Health Inventory; Min-Max, minimum and maximum; PerH, perceived health; Phy, physical health; SHS, Subjective Happiness Scale; WSS, Work Satisfaction Scale. aim is solely to characterise the sample, the subscales can be computed using the arithmetic mean of the items for each participant. In both cases, higher values correspond to: (1) more unfavourable PYJ, (2) more favourable ATO and (3) more unfavourable perception of YH.

\section{Measures to study the convergent validity}

Other measures besides ASSET were also collected in this study. These measures were meant to allow a more detailed study of the impact of the employment strategies on mental health, for instance, work-family conciliation. Next, we describe the measures used to test ASSET convergent validity.

\section{Health and lifestyles}

Three aspects were measured. First, the perceived health (PerH), using one item, 'How would you classify your general health state during the last 3 months', and a 3-point Likert scale (1, good; 2, reasonable and 3, bad). Second, the practice of physical exercise was measured using both a practice frequency and quality (considering an ideal exercise plan) scale. A general index on physical health (Phy) was computed where the original items were recoded so that higher values correspond, respectively, to higher frequency and commitment. After this recoding, the index was calculated with the average of the two variables for each participant. The resulting variables vary between 1 and 6 , and higher values represent higher success in the practice of Phy. Third, medication consumption (Med) was measured using a dichotomous scale (1, yes and 2, no) for a set of 14 clinical conditions (ie, blood pressure, anxiety, depression, stomach problems, sleep, concentration, allergies, cholesterol, diabetes and other conditions).

\section{Biomedical indexes}

A set of 260 participants also took part in the measurement of biomedical indexes through blood samples, anthropometric parameters and blood pressure. Three indexes were computed using the biomedical measures. First, an index to identify the presence of metabolic syndrome (Met). In line with the recommendations of the European Society of Cardiology,${ }^{18}$ we considered Met whenever three or more of the following criteria were met: (1) waist circumference higher than $102 \mathrm{~cm}$ in men and $88 \mathrm{~cm}$ in women, (2) triglycerides higher or equal to $150 \mathrm{mg} / \mathrm{dL}$, (3) cholesterol high-density lipoprotein inferior to $40 \mathrm{mg} / \mathrm{dL}$ in men and $45 \mathrm{mg} / \mathrm{dL}$ in women, (4) systolic blood pressure superior to $130 \mathrm{~mm} \mathrm{Hg}$ and diastolic blood pressure superior to $85 \mathrm{~mm} \mathrm{Hg}$ and (5) glycaemia superior or equal to $100 \mathrm{mg} / \mathrm{dL}$. Second, an index for cardiovascular risk (Card), based on the norms of the Portuguese Society of Cardiology ${ }^{19}$ and, accordingly, we assigned the value of 1 whenever each one of the following risk factors (to a maximum total of 9 ) is present: (1) smoker, (2) high blood pressure (systolic blood pressure superior to $120 \mathrm{~mm} \mathrm{Hg}$ and diastolic blood pressure superior to $80 \mathrm{~mm} \mathrm{Hg}$ ), (3) diabetes (glycaemia higher 


\begin{tabular}{lccccccccc}
\multicolumn{7}{l}{ Table 4} & \multicolumn{7}{c}{ Bivariate correlations between the PYJ and the ATO subscales and the WSS } \\
\hline & WLB & J & JS & O & WR & RC & C & CEO & COE \\
\hline J & $0.57^{*}$ & - & - & - & - & - & - & - & \\
JS & $0.46^{*}$ & $0.67^{*}$ & - & - & - & - & - & - & \\
O & $0.85^{*}$ & $0.67^{*}$ & $0.37^{*}$ & - & - & - & - & - & \\
WR & $0.68^{*}$ & $0.88^{*}$ & $0.64^{*}$ & $0.69^{*}$ & - & - & - & - & \\
RC & $0.51^{*}$ & $0.86^{*}$ & $0.56^{*}$ & $0.52^{*}$ & $0.92^{*}$ & - & - & - & \\
C & $0.52^{*}$ & $0.89^{*}$ & $0.55^{*}$ & $0.57^{*}$ & $0.84^{*}$ & $0.93^{*}$ & - & - & \\
CEO & -0.05 & $-0.37^{*}$ & $-0.28^{*}$ & -0.06 & $-0.27^{*}$ & $-0.32^{*}$ & $-0.28^{*}$ & - & \\
COE & 0.05 & $-0.37^{*}$ & $-0.29^{*}$ & -0.07 & $-0.28^{*}$ & $-0.33^{*}$ & $-0.29^{*}$ & $0.95^{*}$ & \\
WSS & $-0.37^{*}$ & $-0.63^{*}$ & $-0.46^{*}$ & $-0.38^{*}$ & $-0.64^{*}$ & $-0.65^{*}$ & $-0.58^{*}$ & $0.49^{*}$ & $0.49^{*}$ \\
\hline
\end{tabular}

${ }^{*} \mathrm{P}<0.01$.

ATO, Attitudes Towards your Organisation; C, control; CEO, commitment of employee to organisation; COE, commitment of organisation to employee; J, job; JS, job security; O, overload; PYJ, Perceptions of Your Job; RC, resources and communication; WLB, work-life balance; WR, work relationships; WSS, Work Satisfaction Scale.

than $100 \mathrm{mg} / \mathrm{dL}$ ), (4) obesity (body mass index higher than $25 \mathrm{~kg} / \mathrm{m}^{2}$ ), (5) high cholesterol (total cholesterol higher than $190 \mathrm{mg} / \mathrm{dL}$ ), (6) sedentary (equal or inferior to 3 on a scale of activity ranging from 1 -always to 6-never), (7) psychosocial stress (equal or inferior to 3 on the ASSET PWB subscale), (8) male and (9) older than 55 years old. The Card results from the sum of the total number of risk factors present vary between 0 and 9 with higher values representing higher risk. Third, an index of Med consisting in the sum of the answers for Med regarding 14 clinical conditions. The resulting index varies between 0 (does not have any medication prescribed by physicians on the 14 clinical conditions) and 14 (takes medication prescribed by physicians for the 14 clinical conditions).

\section{Mental Health Inventory (MHI-5)}

The MHI-5 is the reduced version of the $\mathrm{MHI}^{20}{ }^{21}$ that measures psychological stress and PWB using 5 items and a frequency scale of 1 , always to 6 , never. Several studies have validated both, the original MHI and the MHI-5. Regarding this one, research has supported the unidimensional structure of the measure as well as the convergent validity with other instruments. ${ }^{22}$ The Portuguese adaptation of the MHI- 5 was conducted by Ribeiro ${ }^{20}$ and replicates the psychometric properties identified in previous studies. In our study, the MHI-5 scale revealed very good internal consistency (alpha $=0.91$ ). In this sense, the final scale was computed using the average of the five items for each participant. In this computation, the measurement was converted into 0 to 100 and items 3 and 5 inverted. In the final scale, the higher the values, the higher the well-being.

\section{Subjective Happiness Scale (SHS)}

The SHS is an instrument that evaluates subjective happiness. This instrument was originally developed by Lyubomirsky and Lepper ${ }^{23}$ and is composed by four items responded on a 7-point Likert scale. The SHS is computed using the arithmetic average of the four items (item 4 is inverted for this computation) and the higher the value, the higher the subjective happiness. In the original paper, Lyubomirsky and Lepper ${ }^{23}$ report results from 14 studies with convergent and discriminant validity and psychometric data supporting the SHS. Pais-Ribeiro ${ }^{24}$ describes the results for the Portuguese validation of the instrument and replicates the results of Lyubomirsky and Lepper. ${ }^{23}$ In our study, the SHS scale has good internal consistency (alpha $=0.84$ ), and consequently, a global score was computed using the average of the 4 items for each participant. These scores vary between 1 and 7 where the higher the value, the higher the subjective happiness.

\section{Connor-Davidson resilience scale (CD-RISC)}

The CD-RISC ${ }^{25}$ is a scale developed to quantify psychological resilience and clinical effects of the treatment of anxiety and depression. It is composed of 25 items measured in a 5-point Likert type scale $(0$-not true to 4-almost always true) and organised in five factors: factor 1 reflects personal competence, high standards and tenacity; factor 2 corresponds to trust in one's instincts, tolerance of negative effect and strengthening effects of stress; factor 3 relates to positive acceptance of change and secure relationships; factor 4 relates to control and factor 5 to spiritual influences. Despite Connor and Davidson's original study ${ }^{25}$ corroborating these five factors, latter studies have reported support for only one factor. ${ }^{26} 27$ In line with this recent literature and considering that the scale with the 25 items reveals good internal consistency (alpha $=0.86$ ), we computed a single global score with the 25 items for each participant. According to this global score, higher values correspond to higher levels of resilience.

\section{Work satisfaction scale (WSS)}

The WSS is a measure of work satisfaction originally part of the Occupational Stress Indicator ${ }^{28}$ and investigated in a Portuguese population by Carochinho and Ferreira. ${ }^{29}$ The composition of the original scale includes 22 items, 7 of which were used in the present 
Table 5 Bivariate correlations between PH and PWB subscales and PerH, Phy, Met, Card and Med

\begin{tabular}{lccccccccc}
\hline & PH & PWB & PerH & Phy & Met & Card & Med & MHI-5 & SHS \\
\hline PWB & $0.88^{*}$ & - & - & - & - & - & - & - \\
PerH & $0.50^{*}$ & $0.45^{*}$ & - & - & - & - & - & - \\
Phy & $-0.17^{*}$ & $-0.14^{*}$ & $-0.22^{*}$ & - & - & - & - & - \\
Met & -0.01 & 0.07 & $0.13^{*}$ & -0.04 & - & - & - & - & - \\
Card & -0.00 & 0.05 & 0.08 & $-0.14^{*}$ & $0.46^{*}$ & - & - & - \\
Med & $0.44^{*}$ & $0.33^{*}$ & $0.39^{*}$ & $-0.14^{*}$ & $0.19^{*}$ & 0.02 & - & - & - \\
MHI-5 & $-0.76^{*}$ & $-0.79^{*}$ & $-0.48^{*}$ & $0.14^{*}$ & -0.01 & -0.01 & $-0.33^{*}$ & - & - \\
SHS & $-0.40^{*}$ & $-0.47^{*}$ & $-0.32^{*}$ & 0.05 & -0.03 & -0.01 & $-0.20^{*}$ & $0.57^{*}$ & - \\
CD-RISC & $-0.31^{*}$ & $-0.44^{*}$ & $-0.15^{*}$ & 0.09 & -0.11 & 0.02 & -0.12 & $0.39^{*}$ & $0.39^{*}$ \\
\hline
\end{tabular}

${ }^{*} \mathrm{P}<0.01$.

Card, cardiovascular risk; CD-RISC, Connor-Davidson Resilience Scale; Med, medication consumption; Met, metabolic syndrome; MHI , Mental Health Inventory; PerH, perceived health; PH, Physical Health; Phy, physical health; PWB, Psychological Well-Being; SHS, Subjective Happiness Scale.

study. These items measure aspects of work satisfaction (eg, promotions and relation with peers) using a 7-point Likert type scale (1-extremely unsatisfied to 7-extremely satisfied). The scale is computed using the arithmetic average of the items where the higher the value, the higher the satisfaction. In our study, the WSS scale revealed a good internal consistency (alpha $=0.88)$. In this sense, a general WSS scale was computed with the arithmetic average for each of the participants in the 7 items.

\section{Procedure}

\section{Translation and adaptation to the Portuguese language}

It was conducted by three translators in the mental health and social sciences fields, with experience in translating from English to Portuguese. For the retroversion, a professional translator was involved. This version of the instrument was submitted to the authors for further appreciation and semantic validation. The final version was then pretested on a random sample of 10 participants and revised accordingly. During this process, it was necessary to adapt some of the questions to the Portuguese reality. First, response options regarding professionals were adapted to the professional groups in our project sample. Second, response options relative to the professional category were adapted to the Portuguese National Classification System. Third, response options regarding marital status were also adapted. Finally, 'do not know' and 'refuses' response options were added whenever necessary.

\section{Survey performance}

The survey was conducted between November 2012 and June 2013 with a response rate of $30 \%$. The whole questionnaire, except for the CD-RISC, was administered electronically. There were two steps in the survey: first, the resilience scale was applied followed by anthropometric measures and second, the survey with ASSET and other scales and questions were sent electronically to each participant. A blood sample was collected from
260 participants, out of the 405. Matching of participants between the survey and blood samples collection was granted using an ID linked to a name and an email address as an identification. For data analysis, only ID was used to guarantee confidentiality.

\section{Psychometric validation}

One of our aims consists in validating the translated version of ASSET. This was performed using a CFA. The statistical quality of the CFA models was assessed using two sets of measures. First, measures of the overall goodness of fit measures considering the following criteria: the root mean square error of approximation (RMSEA) lower or equal to 0.10, Comparative Fit Index (CFI) and Tucker-Lewis Index (TLI) higher or equal to 0.90 . An additional study of the models was performed using measures of the localised areas of strain, specifically, the general modification index (MI) and the factorial weights of the items. Finally, we note that every scale computed used CFA model solution scores. ${ }^{30}$

\section{Convergent validity}

Another aim of this paper is to provide data for the convergent validity of the ASSET subscales, in particular the $\mathrm{YH}$ subscales. The convergent validity is a form of validation that tests for the association between a construct measured by a scale and other measures that theoretically related to this construct. ${ }^{31}{ }^{32}$ For the convergent validity of the ASSET subscales, a set of variables used in the survey of the project were selected, and bivariate correlations were computed (online supplementary table 2). First, owing to the sample dimension and to characteristics of the variables studied, only correlations with a $\mathrm{P}$ value equal or lower than 0.01 are considered statistically significant. ${ }^{33}$ Second, for the interpretation, we consider correlation values inferior to 0.20 as weak correlations, between 0.20 and 0.60 as moderate correlations and 
higher than 0.60 strong correlations (online supplementary table 2 ).

\section{RESULTS}

\section{Psychometric validation}

The ASSET items were studied for situations that can influence factors stability under the CFA, namely, outliers, missing data, asymmetric frequency distributions and low correlation coefficients. The analysis did not reveal any considerable concerns on this regard. In this sense, three models were computed: one with the 36 items of the PYJ loading on seven specific factors-WR, O, C, JS, RC, WLB, $\mathrm{J}$ and $\mathrm{PB}$; one with the 9 items of the ATO loading on two factors-CEO and COE and, finally, one model with the 17 items of the $\mathrm{YH}$ theme loading on two factors- $\mathrm{PH}$ and PWB (table 2).

\section{Perceptions of Your Job}

The model for the PYJ revealed an unacceptable adjustment, $\chi^{2}(573)=1824.34, \mathrm{P}<0.00$, RMSEA $=0.07(0.07,0.08)$, $\mathrm{CFI}=0.77$, TLI $=0.75$, with CFI and TLI values below the criteria. A more detailed study of the model revealed that 7 of the 36 items had low factorial weights $(\lambda<0.40), 5$ items had residuals correlating strongly between factors, and 4 items had residuals correlating strongly within the same factor. A new model without the 11 problematic items and correlating the residuals of the items within the same factor was computed. This new model for the PYJ revealed a more acceptable adjustment, $\chi^{2}(278)=861.46$, $\mathrm{P}<0.001$, RMSEA $=0.07$ (0.06, 0.07), CFI $=0.85$, TLI $=0.82$, although the CFI and TLI measures still are slightly below the 0.90 criteria. Based on these results, seven scales (WR, $\mathrm{O}, \mathrm{C}$, JS, RC, WLB, J and PB) were created using the new model solution scores of the CFA. Additional scales were computed solely for descriptive proposes using the arithmetic average of the participants (table 2).

\section{Attitudes Towards your Organisation}

The model for the ATO revealed an unacceptable adjustment, $\chi^{2}(26)=318.09, \mathrm{P}<0.00$, RMSEA $=0.17(0.15,0.18)$, $\mathrm{CFI}=0.84$, TLI $=0.78$, with RMSA, CFI and TLI values far from the criteria. A more detailed study of the model revealed that 1 of the 9 items had low factorial weights $(\lambda<0.40), 1$ item had residuals correlating strongly between factors, and 4 items had residuals correlating strongly within the same factor. A new model without the two problematic items and correlating the residuals of the items within the same factor was computed. This new model for the ATO revealed a more acceptable adjustment, $\chi^{2}(12)=60.03, \mathrm{P}<0.00$, RMSEA $=0.09(0.075,0.12)$, $\mathrm{CFI}=0.95$, TLI $=0.93$, although the RMSEA is still close to the 0.10 criteria. Based on these results, the two scales (CEO and $\mathrm{COE}$ ) were created using the new model solution scores of the CFA, and additional scales were also computed solely for descriptive purposes using the arithmetic average of the participants (table 2).
Your health

The model for YH revealed an acceptable adjustment, $\chi^{2} \quad(114)=352.73, \quad \mathrm{P}<0.00, \quad \mathrm{RMSEA}=0.07 \quad(0.06,0.08)$, $\mathrm{CFI}=0.94$, TLI $=0.92$. A more detailed study of the model revealed that all factorial weights were high $(\lambda<0.40)$, and no residuals had strong correlations between factors. Based on these results, the two scales (PH and PWB) were created using the new model solution scores of the CFA. Again, additional scales were also computed solely for descriptive proposes using the arithmetic average of the participants (table 2).

\section{Convergent validity}

\section{PYJ and ATO}

The convergent validity of the PYJ and ATO subscales resulting from the CFA models was conducted using the WSS scale (table 3 ). The results of the bivariate correlations (table 4) show that all of the PYJ subscales correlate significantly and in the expected direction with the WSS. Specifically, the PYJ subscales all correlate negatively with the WSS indicating that the less unfavourable the perceptions about the job (as measured by ASSET), the higher the satisfaction with the job (as measured by the WSS).

The results of the bivariate correlations show, again, as expected, that both ATO subscales have a positive moderate correlation with the WSS (both $\mathrm{r}_{\mathrm{s}}=0.49$ ). This correlation indicates that the more favourable the ATO and towards the worker (as measured with ASSET), the higher the work satisfaction (as measured by the WSS).

Finally, it is noteworthy that all the PYJ and ATO subscales have significant correlations among themselves. This result suggests that these subscales are measuring similar aspects of work and stress but still, considering the correlation values not completely superimposable. The only exceptions here are the correlations between WR and RC ( $r=0.93)$ and between both ATO subscales $(r=0.95)$, the first suggesting redundancy between resources and work relations and the second between the attitudes of worker and organisation towards each other.

\section{Your health}

For the convergent validity of the PH subscale, five sets of measures were used (table 3): the single item on PerH, the index of Phy, the index of Met, the index of Card and the index on Med. The results for the bivariate correlations between the $\mathrm{PH}$ and the health variables considered for the convergent validation indicate that PerH, Phy and Med have significant correlations and in the expected direction (table 5). More specifically, the results show: (1) a moderate positive correlation with PerH, where the more unfavourable the PerH (as measured by our single item), the more unfavourable the Phy (as measured by the ASSET; $r=0.50$ ), (2) a weak negative correlation with Phy, where the less successful the practice of exercise (as measured by our index), the more unfavourable the Phy (as measured by the ASSET; $\mathrm{r}=-0.17$ ) and (3) a moderate positive correlation with Med where the higher the consumption of prescribed 
medicine (as measured by our index), the more unfavourable the Phy (as measured by the ASSET; $r=0.44$ ). The results also show that the PH subscale does not correlate significantly with Met and Card. Finally, the analysis of the correlations among the variables used to test the convergent validity themselves shows significant correlations between all the measures except for: Met that only correlates significantly with Card ( $\mathrm{r}=0.46)$ and Card that, additionally, correlates significantly with Phy $(\mathrm{r}=-0.14)$.

To test the convergent validity of the PWB subscale, we computed bivariate correlations between the PWB and three scales: MHI-5, SHS and CD-RISC (table 4). The results of the bivariate correlations show that the PWB subscale and the MHI-5, SHS and CD-RISC scales correlate significantly and in the expected direction (table 5). Specifically, PWB has: (1) strong negative correlation with the MHI-5, where the higher the mental health (as measured by the MHI-5), the less unfavourable the PWB (as measured by the ASSET; $r=-0.79$ ), (2) moderate negative correlation with the SHS, where the higher the subjective happiness (as measured by the SHS), the less unfavourable the PWB (as measured by the ASSET; $r=-0.47$ ) and (3) moderate negative correlation with CD-RISC, where the higher the resilience (as measured by the CD-RISC), the less unfavourable the PWB (as measured by the ASSET; $r=-0.44$ ). The analysis of the correlations between the scales used for the convergent validity of the PWB themselves shows that all these measures correlate significantly and in the expected direction.

Finally, the analysis of the remaining bivariate correlations allows for the following considerations. First, the variables used to test the convergent validity of the $\mathrm{PH}$ subscale-PerH, Phy and Med-are significantly correlated with PWB. Second, the variables used to test the convergent validity of the PWB-MHI-5, SHS and CD-RISC-are, similarly, correlated with the $\mathrm{PH}$. Third, the correlation of the variables in the convergent validity tests shows that: (1) Met and Card are not significantly correlated with MHI-5, SHS and CD-RISC, (2) on the other hand, PerH correlates significantly with these same three instruments, (3) Phy also correlates significantly with MHI-5 and (4) Med is significantly correlated with MHI-5 and SHS.

\section{DISCUSSION}

ASSET is an instrument that measures the levels of stress among workers, and it has been widely used in organisational contexts. However, despite the general relevance of stress and of ASSET, there is no version in use by more than 270 million people belonging to the Community of Portuguese Language Countries. In this paper, we describe the translation, adaptation and psychometric data regarding the Portuguese version of ASSET. Additionally, we also test for the convergent validity of ASSET, in particular regarding the $\mathrm{PH}$ and PWB subscales.
First, the translation of the scale revealed the need only for minor adaptations to the Portuguese reality (eg, the professional categories). Second, the results for the CFA revealed that the original models for the PYJ and ATO subscales did not have a good statistical fit. Still, minor adjustment using the factorial weights and MIs as a criteria to remove some of the problematic items allowed to create two models with an acceptable fit. ${ }^{\mathrm{i}}$ On the other hand, the results for the $\mathrm{YH}$ model revealed an acceptable fit without any additional adjustments.

Regarding the study of convergent validity, first, the results indicate that all the PYJ subscales have significant correlations in the expected direction with the WSS. More specifically, all the PYJ subscales have negative correlation with the WSS indicating that the less unfavourable the perceptions of the job (as measured by ASSET), the higher the job satisfaction is (as measured by the WSS). The results also show that, as expected, the ATO subscale has a significant positive correlation with WSS indicating that the higher the ATO (as measured by ASSET), the higher the job satisfaction (as measured by the WSS). The relation between the WSS and the PYJ and ATO subscales adds to previous evidence showing that these subscales are measuring substantive labour issues related with satisfaction and productivity. Additionally, the existence of differences in the strength of the correlations between the WSS and the PYJ and ATO subscales potently reflect the specific nature of these subscales. For instance, our results show that the WSS has the strongest correlation with WR and the lowest correlation with WLB suggesting that WR might be more important to work satisfaction than work-life balance.

Second, the relation between the set of measures used to test the convergent validity of $\mathrm{YH}$ subscales provides a good demonstration that these subscales are, indeed, measuring physical and mental health. More specifically, the results indicate that the subscale PH correlates significantly and in the expected direction with PerH, Phy and Med. Noteworthy that, contrary to our predictions, $\mathrm{PH}$ does note correlate with Met and Card indexes. These results are not surprising if we take into account the characteristics of our sample. In fact, the variability of these indexes is extremely low-only $12 \%$ of the participants show Met and more than $75 \%$ of the participants have a risk of cardiovascular diseases lower than 4 on a scale of 0 to 9 . An alternative explanation is that the physiological parameters are not registered in perceptions of individual health when they are not symptomatic. In this sense, the usage of clinical measures should be regarded with caution when studying psychological constructs such as organisational stress. Regarding the

${ }^{\mathrm{i}}$ For practical use, we still advise keeping the original structure of the subscales and to use CFA, in a similar fashion to the one described here, to test for the fit of subscales. 
PWB subscale, the results also depict significant correlations in the predicted direction with MHI-5, SHS and CD-RISC. More specifically, the results show that the more unfavourable the PWB (as measured by ASSET), the lower the mental health (as measured by the MHI-5), the lower the subjective happiness (as measured by the SHS) and the lower the resilience (as measured by the CD-RISC).

Globally, the results of the convergent validity of $\mathrm{YH}$ subscales are extremely important. First, the instruments used for this validation (MHI-5, SHS and CD-RISC) are well known, validated and widely used in the mental health literature. Moreover, although these instruments relate among themselves, they tackle into different aspects of mental health involving distress, well-being and resilience. Additionally, complementary measures with important ecological value were also used ( $\mathrm{PerH}$ and Phy). This allowed to test the relation between the YH subscales and more general perceptions regarding health and Phy. In this sense, our results for the convergent validity support that the ASSET YH subscales provide, in fact, good measurements of physical and mental health. This is particularly important once ASSET is expected to evaluate the factors associated with the risk of stress of workers at an organisation, and mental and physical health are known to be important dimensions on this regard.

\section{CONCLUSION}

The results of our study provide structural support for ASSET, both from the psychometric and validity perspectives. In fact, it is important to notice that the number of studies addressing the convergent validity of this instrument is scarce, reason why our results are particularly useful to create critical awareness. Additionally, our results also provide a stimuli for further research of the psychometric characteristics of ASSET, in particular with the PYJ and ATO subscales that were found more difficult to replicate from the original results. But most important, this study found a predictive validity of the mental and physical health scales and clinical measures of health in both these arenas. Finally, this paper opens the opportunity for the Community of Portuguese Language Countries to use ASSET to address appropriately and in detail the stress risk at different work settings.

Acknowledgements We thank Maria do Céu Machado (former High Commissioner for Health-ACS) and Francisco George and Catarina Sena (Directorate General of Health-DGS) for their financial support; the National Institute of Health Dr Ricardo Jorge (INSA, IP), in particular Astrid Vicente, Mafalda Bourbon, Carlos Dias, Baltazar Nunes, Marta Barreto, Isabel Carvalho-Oliveira, Isabel Picanço and Joana Canilho; the Administration of Montepio Geral (CEMG) and Maria do Carmo Bragança and Helena Pita Soares; the National School of Public Health, in particular João Pereira, Isabel Loureiro, Pedro Aguiar and Filipe Rocha; Marta Godinho, Elisa Lopes, Alexandra Dinis and Jack Evans and the participants at this study, employees at CEMG.

Contributors MJHdS: contribution to the research - PhD student and principal investigator, mentor of the research project Health Impact Assessment (HIA) of Employment Strategies, responsible for submitting the project for funding, strategic planning, project management, recruting collaborators and coordinaton of all involved entities, collaborators, experts, researchers and consultants at national and international levels; contribution to the final document - instrument acquisition, instrument translation to the Portuguese version, reviewing and writing the document to its final version. JC: contribution to the research - tecnhical, administrative and executive management support of the research project Health Impact Assessment (HIA) of Employment Strategies, collaboration at data collection, fieldwork supervision, preliminary data analysis and results dissemination support; contribution to the final document - instrument translation to the Portuguese version, collaboration in the writing of the first version of the document, references organisation. SM: contribution to theresearch - statistical data analysis of the collected data, results interpretation and report of the research project Health Impact Assessment (HIA) of Employment Strategies; contribution to the final document - statistical data analysis of the collected data with the Portuguese version of ASSET, data interpretation and presentation in ASSET technical statistics report. CC: contribution to the research - expert consultant of theresearch project Health Impact Assessment (HIA) of Employment Strategies; contribution to the final document - back translation review. MS: contribution to the research - expert consultant of the research project Health Impact Assessment (HIA) of Employment Strategies; contributionto the final document - review of data interpretation in a first phase of data analysis and review of a prefinal version of the paper. JPM: contribution to the research - thesis advisor; contribution to the final document - document review. MdFR: contribution to the research - thesis co-advisor; contribution to the final document - document review.

Funding The project Health Impact Assessment (HIA) of Employment Strategies was funded through a protocol celebration between the former Portuguese Office of the High Commissioner for Health (ACS), the National Institute of Health Doutor Ricardo Jorge, Public Institute (INSA, IP), the Institute of Preventive Medicine and Public Health of the Faculty of Medicine of the University of Lisbon (IMP\&SP, FMUL) and the General Directorate of Health (DGS, IP) in Portugal.

Competing interests ASSET is a psychometric measure developed by the University of Manchester spin-off company Robertson Cooper, a company of which the author CC is a director, with the University being the largest shareholder. ASSET has been published widely in the scholarly literature.

Patient consent Obtained.

Ethics approval The project Health Impact Assessment (HIA) of Employment Strategies was approved by the Ethics Committee for Health of the National Institute of Health Doutor Ricardo Jorge, Public Institute (INSA, IP), the Ethics Committee for Health of the Lisbon/North Hospital Center of Faculty of Medicine of the University of Lisbon (CHLN/FMUL) and also by the National Commission of Data Protection (CNPD), Portugal.

Provenance and peer review Not commissioned; externally peer reviewed.

Data sharing statement Extra data may be available by emailing MJHdS at mjhsantos@netcabo.pt

Open Access This is an Open Access article distributed in accordance with the Creative Commons Attribution Non Commercial (CC BY-NC 4.0) license, which permits others to distribute, remix, adapt, build upon this work non-commercially, and license their derivative works on different terms, provided the original work is properly cited and the use is non-commercial. See: http://creativecommons.org/ licenses/by-nc/4.0/

C Article author(s) (or their employer(s) unless otherwise stated in the text of the article) 2018. All rights reserved. No commercial use is permitted unless otherwise expressly granted.

\section{REFERENCES}

1. Buckley P. Work related stress, anxiety and depression statistics in Great Britain 2016 [Internet]. UK (ON): Health and Safety Executive. www.hse.gov.uk/statistics/

2. Pohling R, Buruck G, Jungbauer KL, et al. Work-related factors of presenteeism: The mediating role of mental and physical health. J Occup Health Psychol 2016;21:220-34.

3. Peter R, Siegrist J, Hallqvist J, et al. Psychosocial work environment and myocardial infarction: improving risk estimation by combining two complementary job stress models in the SHEEP Study. $J$ Epidemiol Community Health 2002;56:294-300.

4. Schonfeld IS, Bianchi R. Burnout and depression: two entities or one? J Clin Psychol 2016;72:22-37. 
5. Niedhammer I, Chastang JF, Sultan-Taïeb H, et al. Psychosocial work factors and sickness absence in 31 countries in Europe. Eur $\mathrm{J}$ Public Health 2013;23:622-9.

6. Donald I, Taylor P, Johnson S, et al. Work environments, stress, and productivity: An examination using ASSET. Int J Stress Manag 2005;12:409-23.

7. Faragher $\mathrm{EB}$, Cooper $\mathrm{CL}$, Cartwright $\mathrm{S}$. A shortened stress evaluation tool(ASSET). Stress and Health 2004;20:189-201.

8. Cooper CL, Marshall J. Occupational sources of stress: a review of the literature relating to coronary heart disease and mental ill health. $J$ Occup Psychol 1976;49:11-28.

9. Johnson S, Cooper C. The construct validity of the ASSET stress measure. Stress and Health 2003;19:181-5.

10. Cartwright S, Cooper CL. ASSET: an organisational stress screening tool the management guide. Manchester, UK: Robertson/Cooper Ltd, 2002.

11. Warr P. The measurement of well-being and other aspects of mental health. J Occup Psychol 1990;63:193-210.

12. Johnson S, Cooper C, Cartwright S, et al. The experience of workrelated stress across occupations. Journal of Managerial Psychology 2005;20:178-87.

13. Cartwright S, Cooper CL. The Oxford handbook of organizational well-being. 1st edn. New York: Oxford University Press, 2009.

14. Hesketh I, Cooper C, Ivy J, et al. peelers poor: Measuring and Efficacy of Resilience training in Policing. Int J Hum Res Manag 2017.

15. CPLP. Comunidade dos Países de Língua Portuguesa. https://www. cplp.org/

16. Johnson S. Organizational screening: The ASSET model. In: Cartwright S, Cooper CL, eds. The Oxford handbook of organizational well-being. Oxford, UK: Oxford University Press, 2009:133-55.

17. Macnab D, Bakker S, Fitzsimmnos G. Career values scale manual and user's guide. Edmonton, Canada: Psychometrics Publishing, 2005.

18. ESC. European Society of Cardiology [Internet]. http://www.escardio. org.

19. Sociedade Portuguesa de Cardiologia. Portuguese Society of Cardiology [Internet]. http://www.spc.pt.
20. Ribeiro JLP. Mental health inventory: Um estudo de adaptação à população portuguesa. Psic, Saúde \& Doenças 2001;2:77-99.

21. Veit CT, Ware JE. The structure of psychological distress and well-being in general populations. J Consult Clin Psychol 1983:51:730-42.

22. Rumpf HJ, Meyer C, Hapke U, et al. Screening for mental health: validity of the MHI-5 using DSM-IV Axis I psychiatric disorders as gold standard. Psychiatry Res 2001;105:243-53.

23. Lyubomirsky S, Lepper HS. A measure of subjective happiness: preliminary reliability and construct validation. Soc Indic Res 1999;46:137-55.

24. Pais-Ribeiro JL. Validação transcultural da escala de felicidade subjectiva de Lyubomirsky e Lepper. Psic, Saúde \& Doenças 2012;13:157-68.

25. Connor KM, Davidson JR. Development of a new resilience scale: the Connor-Davidson resilience Scale (CD-RISC). Depress Anxiety 2003;18:76-82.

26. Campbell-Sills L, Stein MB. Psychometric analysis and refinement of the Connor-davidson Resilience Scale (CD-RISC): Validation of a 10-item measure of resilience. J Trauma Stress 2007;20:1019-28.

27. Kararmak O. Establishing the psychometric qualities of the Connor-Davidson Resilience Scale (CD-RISC) using exploratory and confirmatory factor analysis in a trauma survivor sample. Psychiatry Res 2010;179:350-6.

28. Cooper CL, Sloan SJ, Williams S. Occupational stress indicator management quide. Windsor: NFER-Nelson, 1988

29. Carochinho JA, Ferreira MA. A satisfação no trabalho: breves considerações teóricas e estudo psicométrico da escala de satisfação no trabalho do OSI. Psicologia: Teoria, Investigação $E$ Prática 2003;8:339-55

30. Brown TA. Confirmatory Factor Analysis for Applied Research. 1st edn: Guilford Press, 2006.

31. Campbell DT, Fiske DW. Convergent and discriminant validation by the multitrait-multimethod matrix. Psychol Bull 1959;56:81-105.

32. Cronbach LJ, Meehl PE. Construct validity in psychological tests. Psychol Bull 1955;52:281-302.

33. Field A. Discovering statistics using SPSS: and sex drugs and rock'n'roll. London: Sage Publications, 2009. 